\title{
ACCUMULATION DETECTION OF SOME HEAVY METALS IN SOME TYPES OF FRUITS IN THE LOCAL MARKET OF AL-DIWANIYAH CITY, IRAQ
}

\author{
Lujain Hussein Ibraheen ${ }^{1}$ and Salwan Ali Abed ${ }^{2, *}$ \\ College of Science, University of Al-Qadisiyah, P.O.Box.1895, Iraq. \\ "E-mail: Salwan.abed@qu.edu.iq
}

\begin{abstract}
The Fruits one of the most important materials in providing the humans daily dietary requirements from vitamins iron, calcium, potassium and some other metals that need in the daily food as dietary supplementation or as an important elements that form some hormones or enzymes in small concentrations, if exists in high concentrations become toxic with bad effects. This study were conducted in order to detect of the concentrations of some heavy metals from samples of fruits in the local markets in Al-Diwaniyah city where they were studying four heavy elements, namely, (lead, copper, chromium, and cadmium) for 10 samples of fruits. The study showed that most of the samples were contaminated with lead and cadmium elements, it shows the highest value for them (29-0.22) ppm and low-pollution component of copper (57) and zero-pollution of chromium element according to the World Health Organization.
\end{abstract}

Keywords: Heavy Metals, Fruit, Local Market, Accumulation, Al-Diwaniyah, Iraq.

(c) RASĀYAN. All rights reserved

\section{INTRODUCTION}

The pollution of heavy metal were considered one of the most important phase of environmental pollution that resulted from human activity of industrial or agricultural, and in recent years, scientists interested in studying the heavy metals in terms of their presence in the environment and biological effects and its relation to human health, it affects health directly and food is considered one of the main sources of human exposure to these metals, so many studies have focused on the development of appropriate methods to determine the extent of contamination of food with these metals and its suitability for human use. And determine the minimum or critical concentration allowed by these contaminants in food without damage occurs. ${ }^{1}$ Generally, some of these metals are toxic like mercury, lead, cadmium and arsenic compounds which is considered harmful to the nervous system and functions of the kidney with some stomach disorders. ${ }^{2}$ The metal contamination of the soil and plants attributed to multiple human activities, from the melting of metals and painting and all other mineral work as well as the leather industry, tanning and other industries that done by the human, which would contaminate the surrounding environment as well as the expansion of cities and their development and the accompanying of many and varied remnants. ${ }^{3}$

The pollution of heavy metals increasing in fruits and vegetables as a result of the impact of fertilizers and pesticides containing these elements. ${ }^{4}$ Different kinds of plants (Thlaspi Brassicaceae) have high ability to absorb heavy metals in the soil of this type lotion which is absorbs $3 \%$ and $0.5 \%$ of the zinc and lead.

The depends of plant's ability to accumulate heavy metals in the tissues on the plant size and the speed of growth and the productivity of biomass because they store these elements in different interweave so the trees are the most suitable for this vital process, where some trees have the ability to adapt and grow in contaminated soils. ${ }^{5}$ Fernandes and Henriques, 1989 have found that the type of plant Quercus rotundifolia that the concentration of zinc, lead and chrome elements in the fruit and growing in soils contaminated with up to 20 times higher than the same growth plant is contaminated with these elements. 


\section{EXPERIMENTAL}

The samples were collected from the local markets in Al-Dwianyah, Al-Qadisiyah Province, Southern Iraq (Figure-1) with the coordinates of latitude $31^{\circ} 59^{\prime} 16.66 " \mathrm{~N}$ and longitude $44^{\circ} 55^{\prime} 27.64 " \mathrm{E}$ by 10 samples for a range of different fruits (oranges, bananas, pomegranates, grapes, lemon, strawberry, buckthorn, peach, apple and paper) and three replicates for each sample of fruit and put special bags and transported to the laboratory where they were washing the samples with water distilled, free of ions and dried at a temperature $(70){ }^{\circ} \mathrm{C}$ for 48 hours and then milled dry samples and pass through a sieve capacity (40) mesh and then taking the weight (0.5) $\mathrm{g}$ of sample and put in a tube digest type Pyrex and added to 5 $\mathrm{ml}$ of nitric acid HNO3 center and left the samples for 16 hours and then digested placing them on the degree of (100) $\mathrm{m}^{\circ}$. And for one hour then add $3 \mathrm{ml}$ of Alberaklorek acid (70\%) and make the samples escalation (reflux) for 30 minutes at a temperature $200^{\circ} \mathrm{m}$ until the solution is clear and the purpose of getting rid of the possibility of the existence of stuck materials in solution is a centrifugal sampling process for (10) minutes and quickly $2000 \mathrm{r} / \mathrm{min}$, then completed the sample size $(50 \mathrm{ml})$ using empty water from ions and put in special plastic containers for the purpose of examination to a nice atomic absorption. ${ }^{6,7}$

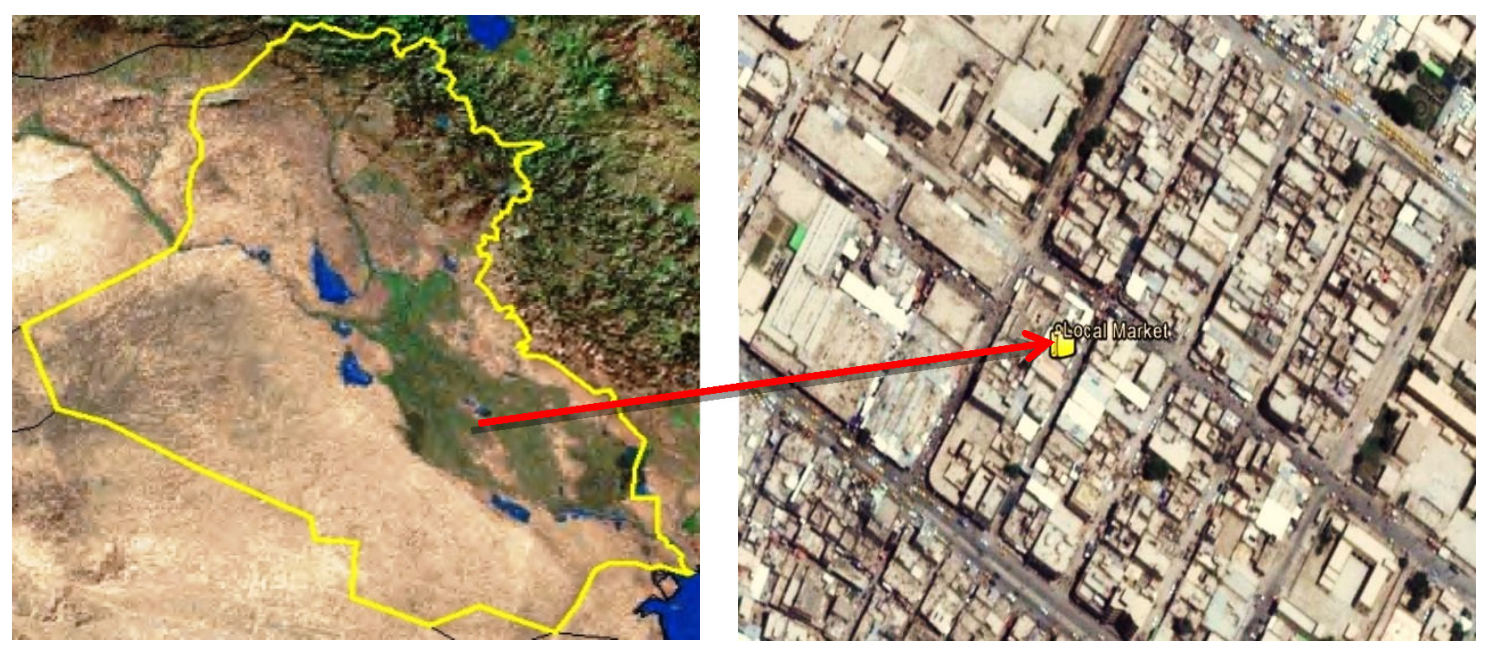

Fig.-1: Study area

\section{RESULTS AND DISCUSSION}

The Heavy metals have been recorded to have some positive and negative roles in life cycle of human, cadmium, lead and mercury are the major contaminants of food supply and may be considered the most important problem issues to our environment. ${ }^{8}$ Based on the data that we got it during our study, the tables and figures below clarify our results.

Table-1: Concentration of heavy metals in the samples studied ppm.

\begin{tabular}{c|c|c|c|c|c}
\hline S. No. & Samples & Cd Concentration & Cr Concentration & Cu Concentration & Pb Concentration \\
\hline 1 & Orange & 0.22 & 100 & 40 & 26 \\
\hline 2 & Banana & 0.13 & 73 & 34 & 13 \\
\hline 3 & Pomegranate & 0.12 & 100 & 57 & 28 \\
\hline 4 & Grapes & 0.15 & 100 & 38.9 & 24 \\
\hline 5 & Lemon & 0.12 & 100 & 47.8 & 29 \\
\hline 6 & Strawberry & 0.07 & 85.9 & 31.3 & 10 \\
\hline 7 & Buckthorn & 0.17 & 87.8 & 35.2 & 20 \\
\hline 8 & Peaches & 0.11 & 70.1 & 21.3 & 11 \\
\hline 9 & Apple & 0.09 & 63.8 & 25.7 & 10.5 \\
\hline 10 & Watermelon & 0.07 & 53.2 & 20.1 & 9.9 \\
\hline
\end{tabular}


RASĀYAN J. Chem.

Vol. 10 | No. 2 |339-343 | April - June | 2017

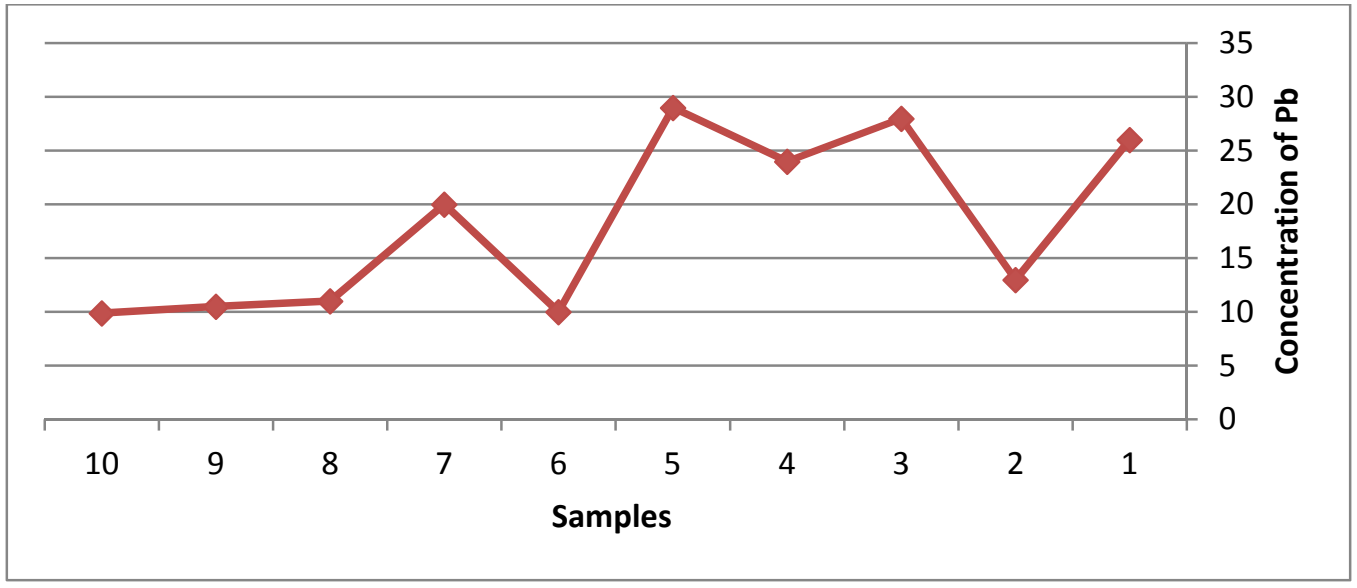

Fig.-1: Concentration of lead element in the samples studied ppm.

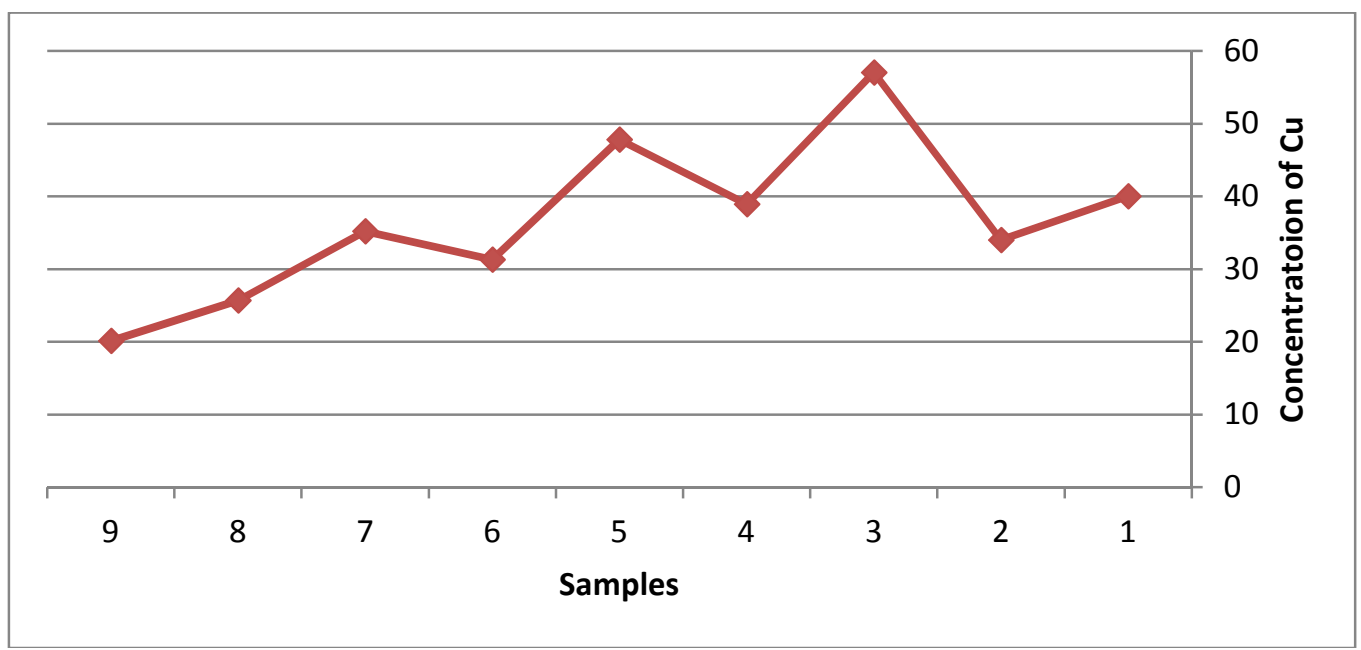

Fig.-2: Copper concentration in the samples studied ppm.

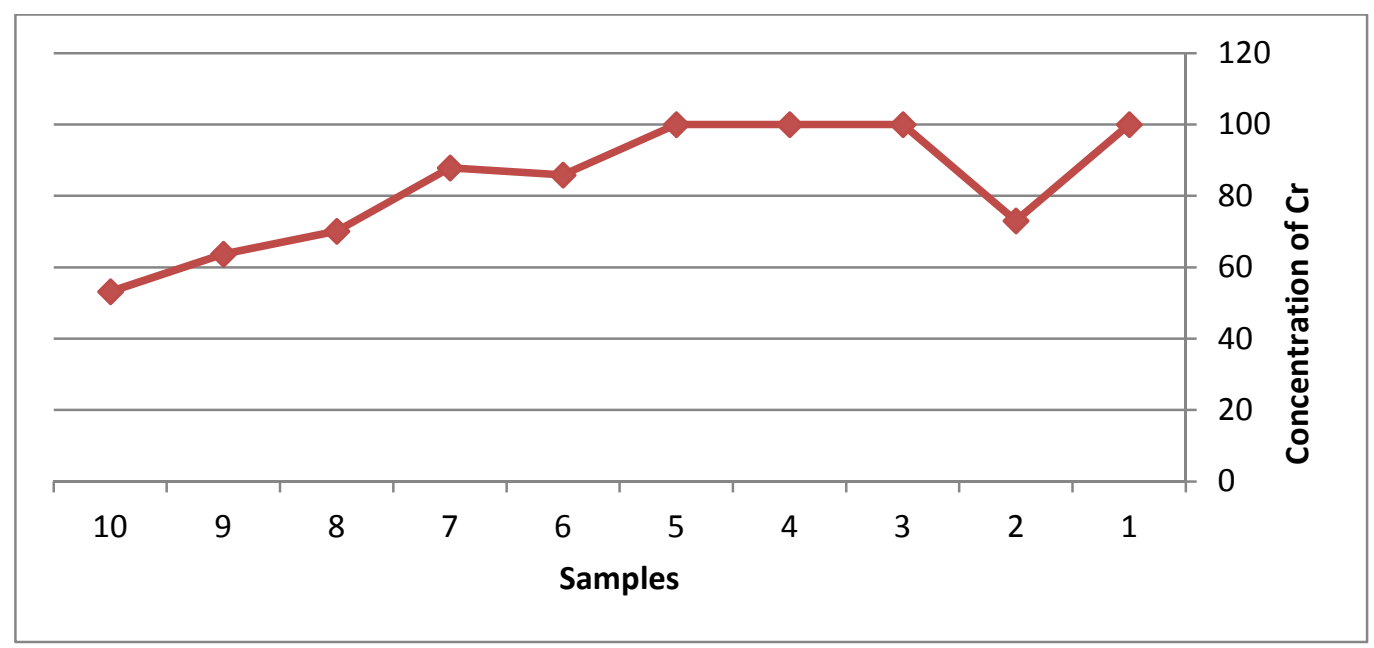

Fig.-3: Chromium concentration in the samples studied ppm 
RASĀYAN J. Chem.

Vol. 10 | No. 2 |339-343 | April - June | 2017

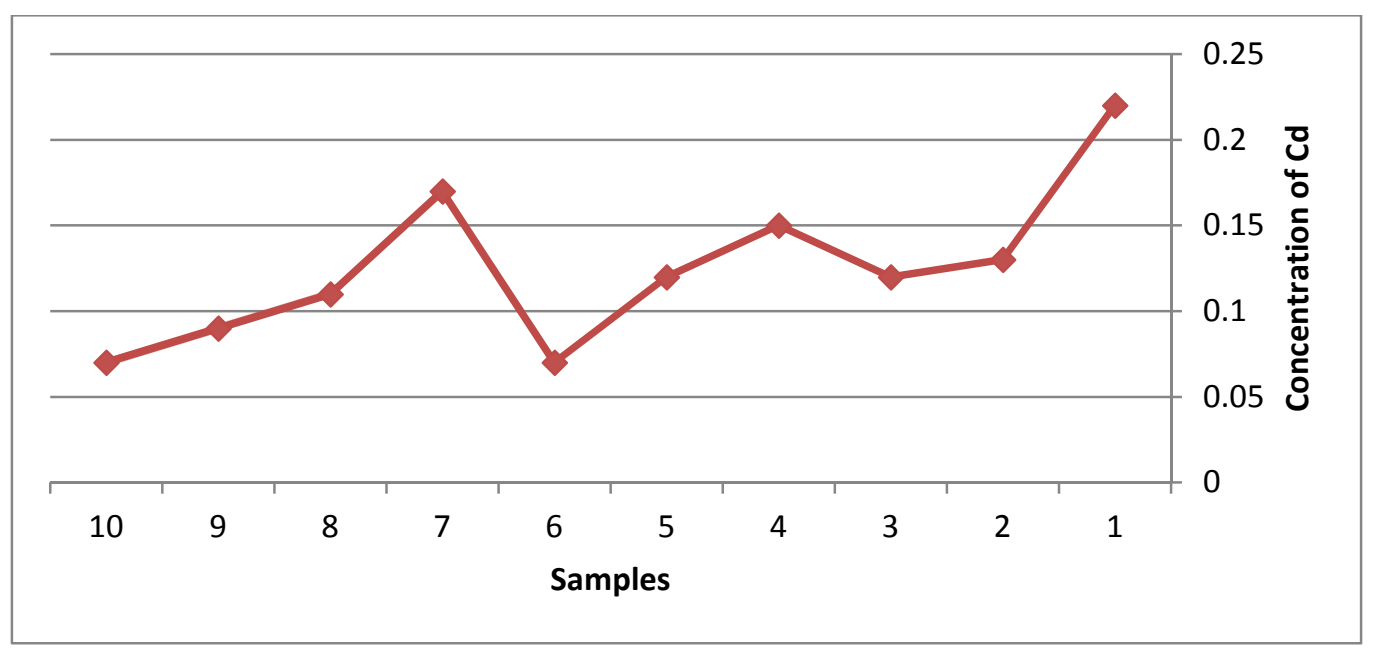

Fig.-4: Concentration of cadmium in the samples studied ppm

Figure-1 shows the concentration of lead element in the samples is noted that the highest concentration was in both (lemons, pomegranates and oranges), reaching $(29,28,26) \mathrm{ppm}$, respectively, and the lowest value was in (watermelon, strawberries and apples) where were reached $(9.9,10$ and 10.5) lead source is the fuel incinerators and solid industry waste metal products of human contamination by and exposed by eating contaminated food by lead or derivatives or through inhalation resulting to accumulate in the blood and also affects the digestive system, immune, kidney and lead replace the calcium in the tissues of the bone and cause a reduction of hemoglobin and increased the concentration will lead to coma and death situations and proved scientifically absorbed by the bodies of the children more than adult. ${ }^{9}$

Figure- 2 shows the concentration of copper in the samples studied where noted that the highest value was in samples of pomegranate and lemon reaching (57 and 47.8) ppm. The lowest value was in watermelon and peach (20.1 and 21.3) ppm. The salts dissolved of copper have a high toxicity which is affect the breathing process significantly. ${ }^{10-12}$

Figure-3 shows the concentration of chromium in the samples studied of fruit noted that the highest values were in the oranges, pomegranates, grapes, lemons which is $100 \mathrm{ppm}$. But it is not considered contaminated because it is the highest permissible limits according to ${ }^{1}$ and the lowest value was in progress and peach reaching (53.2 and 70.1) ppm, and lower than the permissible limits by the World Health Organization.

Figure-4 shows that the concentration of cadmium in the samples studied fruit notes that the highest value of orange samples, buckthorn, and grapes were $(0.22,0.17$ and 0.15$) \mathrm{ppm}$. The lowest value when samples, watermelon strawberries and apples was (0.07 and 0.09) ppm.

The study notes that the samples of watermelon and strawberry samples are not contaminated with all the studied elements as mentioned by ${ }^{5,13}$ to the accumulation of heavy metals depends on the biomass and the size and age of the plant and for the same reason noted the highest concentrations in the orange, lemon and buckthorn. The pollutants were higher than the metals of lead and cadmium. The data is compiled and presented in Table-1.

\section{REFERENCES}

1. FAO/WHO, Joint FAO/WHO food standers program, codes Aliment Arius commission contamination. FAO, Roma CAC/ Vol. XV, 11, 56 (1984).

2. G. Ysart, P. Miller, M. Croasdale, H. Crews, P. Robb, M. Baxter, C. deL'Arge and N. Harrison, Food Additives and Contaminants, 17(9), 775 (2000).

3. R.A. Goyer, Toxic effects of metals In Casarett and Baull's toxicology, The basic science of poisons (Eds. C. D. Klaassen, M. O. Amdur and J. Doull), Macmillan Publishing Company, New York, 528, (1986). 
4. Harith Mahmoud, Diyala Journal of Agricultural Science, 3 (1) ,34 (2011).

5. $\mathrm{Zu}$ Yanqun, Li Yuan, Ch. Schvartz, L. Langlade and L. Fan, Environment International, 30, 567(2004).

6. S. Onder, S. Dursuns, S. Gezgin and A. Demirbas, Polish J. of Environ. Stud. , 16 (1) ,145 (2007).

7. M.M. Antoni jevic and M. Maric, Sensoers, , 8 ,5857(2008).

8. Maha Bashir Omer, Assessment of Some Heavy Metals in Fruit from Local Market in Khartoum State, Sudan Academy of Sciences, M.Sc. Thesis, p.1,2. (2015).

9. Bassam Alagy, Soil Pollution, Pesticide, Syria, 1, 77 (2015).

10. Al- Subaie, Fahad bin Nasser Eid, Muhammad ibn Abd al-Rahman and Hani bin Menem Hamshary, Examining the canned food contamination with elements of heavy metals, nitrates and nitrites. Master Thesis, Faculty of Agricultural and Food Sciences. King Faisal University, p.89 (2014).

11. Ahmed Alsroe, Water pollutants (source, influence, control and treatment), Dar scientific books for publication and distribution, Cairo, Egypt., 115 (2008).

12. Al- Maliki, Maitham Abdulla Sultan, Evaluation of air pollutants, water and soil in the city of Baghdad by using geographical information system (GIS), PhD Thesis. College of Science. Baghdad University, p.45. (2005).

13. J. C. Fernandes and F.S. Henriques, Water ,Air, Soil Pollut., 48, 409(1989).

[RJC-1641/2017] 